\title{
STRATEGI PENGEMBANGAN USAHA KECIL MENENGAH SEKTOR INDUSTRI PENGOLAHAN
}

\author{
ARIEF RAHMANA ${ }^{1}$, YANI IRIANI ${ }^{2}$, DAN RIENNA OKTARINA ${ }^{3}$ \\ Program Studi Teknik Industri, Universitas Widyatama \\ E-mail: arief.rahmana@widyatama.ac.id
}

\begin{abstract}
ABSTRAK
Paradigma yang mendasari penelitian ini adalah bahwa UKM telah memberikan kontribusi terhadap pertumbuhan ekonomi, yang ditunjukkan kontribusi terhadap penyerapan tenaga kerja sebesar $99,74 \%$ dari total serapan nasional dan memberikan kontribusi terhadap Produk Domestik Bruto (PDB) sebesar Rp 1.013,5 triliun atau 56,73\%. Namun demikian, dalam pengembangannya menghadapi beberapa masalah di antaranya adalah kurang permodalan, kesulitan dalam pemasaran, struktur organisasi sederhana dengan pembagian kerja yang tidak baku, kualitas manajemen rendah, SDM terbatas dan kualitasnya rendah, kebanyakan tidak mempunyai laporan keuangan, aspek legalitas lemah, dan rendahnya kualitas teknologi. Berdasarkan hal ini, diperlukan strategi yang komprehensif agar UKM berkembang lebih cepat, permasalahan yang dihadapi dapat direduksi, dan memiliki keunggulan kompetitif. Rumusan strategi pengembangan yang diusulkan adalah menggunakan integrasi pendekatan location quotient (LQ), diamond cluster model, dan analisis SWOT. Hasil penelitian menunjukkan bahwa UKM yang mempunyai potensi yang besar untuk dikembangkan adalah sektor Industri Pengolahan karena memiliki nilai indeks LQ terbesar yaitu 4,277. Selanjutnya strategi pengembangan UKM adalah strategi ST, yaitu strategi menggunakan kekuatan (strength) untuk mengatasi ancaman (threat). Dengan strategi ini, sebaiknya UKM melakukan diversifikasi produk presisi dengan menggunakan teknologi CNC, CAD, dan CAM, meningkatkan kualitas produk, dan membina kerja sama yang intensif dengan para supplier untuk memperoleh pasokan bahan baku yang memadai.
\end{abstract}

Kata kunci: UKM, industri pengolahan, location quotient, diamond cluster model, analisis SWOT

\begin{abstract}
The paradigm underlying this research is that SME has contribution to economic growth, that is indicated by their contribution to employment and Gross Domestic Product. SMEs contribute to employment more than 99,7 per cent of national employment and contribute to more IDR 1,013.5 trillion or 56,73 per cent. Nevertheless, the developing of SME's facing some problems namely lack of capital, difficulties in marketing, simple organizational structure with unstandard job description, low of quality management, limited human resource, generally it has no finanacial accounting, low of legality aspect, and low of technology quality. According to this matter, a comprehensive strategy for developing SME's is very crusial to develop in order to fasten SME's growth, to eliminate SME's problems, and to make SME's competitive. The strategy composed based on integration of location quotient, diamond cluster model, and SWOT analysis approach. The result indicated that SME's which have big potential to develop are manufacturing industry sector, because it has the biggest value of $L Q$ is about 4,277. Then, strategy for developing SME's is ST strategy, namely using some strength to overcome some threats. According to this strategy, SME's should carry out product diversification by using CNC, CAD, and CAM technology, improve quality of product, and cooperate with suppliers to get supply raw material.
\end{abstract}

Key words: SMEs, manufacturing industry, location quotient, diamond cluster model, SWOT analysis

\section{PENDAHULUAN}

Pengembangan UKM menjadi suatu hal yang krusial mengingat UKM mempunyai peranan yang demikian penting untuk pertumbuhan ekonomi sebuah negara termasuk di negara Indonesia (Husband and Purnendu, 1999; Tambunan, 2005). Sebagai ilustrasi, UKM di Indonesia telah memberikan kontribusi terhadap penyerapan tenaga kerja sebesar 99,74\% dari total serapan nasional dan memberikan kontribusi terhadap PDB sebesar Rp
1.013,5 triliun atau 56,73\%. Besarnya kontribusi ini, menunjukkan bahwa UKM mempunyai kemampuan untuk memperkuat struktur perekonomian nasional (Prawirokusumo, 2001). Meskipun secara ekonomi UKM mempunyai kontribusi yang signifikan terhadap pertumbuhan ekonomi, namun dalam pengembangnnya menghadapi berbagai permasalahan. Menurut penelitian Winarni (2006) dan Situmorang (2008) permasalahan yang dihadapi UKM, disarikan sebagai berikut: 
(a) kurang permodalan, (b) kesulitan dalam pemasaran, (c) struktur organisasi sederhana dengan pembagian kerja yang tidak baku, (d) kualitas manajemen rendah, (e) SDM terbatas dan kualitasnya rendah, (g) kebanyakan tidak mempunyai laporan keuangan, (h) aspek legalitas lemah, dan (j) rendahnya kualitas teknologi. Permasalahan ini mengakibatkan lemahnya jaringan usaha, keterbatasan kemampuan penetrasi pasar dan diversifikasi pasar, skala ekonomi terlalu kecil sehingga sukar menekan biaya, margin keuntungan sangat kecil, dan lebih jauh lagi UKM tidak memiliki keunggulan kompetitif.

Melihat berbagai permasalahan yang dihadapi dalam pengembangan UKM, maka dibutuhkan suatu strategi pengembangan UKM agar perkembangan UKM di Indonesia berjalan dengan cepat, permasalahan yang dihadapi UKM dapat direduksi, dan UKM mempunyai keunggulan yang lebih kompetitif (Hafsah, 2004). Dengan demikian, semua permasalahan yang dihadapi UKM sebaiknya dijadikan input atau bahan pertimbangan dalam merumuskan strategi pengembangannya agar strategi tersebut bersifat komprehensif dan dapat berjalan secara efektif dan efisien. Berbagai penelitian tentang strategi pengembangan UKM di Indonesia telah dilakukan, di antaranya oleh Winarni (2006), Hafsah (2004), dan Situmorang (2008). Pada dasarnya strategi pengembangan UKM yang diusulkan oleh para peneliti tersebut tidak berbasis keunggulan atau potensi lokal (potensi UKM) dan peluangpeluang eksternal, serta strategi pengembangan yang diusulkan masih didasarkan pada pendekatan kualitatif.

Penelitian ini mencoba membuat suatu strategi pengembangan UKM yang mengintegrasikan keunggulan atau potensi lokal UKM dengan peluangpeluang eksternal yang ada. Secara makro, strategi yang dirumuskan dalam penelitian ini diawali dengan melakukan analisis potensi dan masalah terhadap setiap sektor UKM yang ada, sehingga mampu mengidentifikasi sektor UKM mana yang lebih berpotensi dan tepat untuk dikembangkan, kemudian dirumuskan strategi pengembangannya berdasarkan pada pendekatan kualitatif dan kuantitatif. Strategi pengembangan UKM didasarkan pada integrasi tiga metode, yaitu location quotient, diamond cluster model, dan analisis SWOT. Location quotient merupakan metode yang akan digunakan untuk menginisiasi sektor UKM mana yang menjadi prioritas untuk dikembangkan. Diamond cluster model digunakan untuk mengidentifikasi faktorfaktor yang menjadi keunggulan bersaing UKM. Analisis SWOT digunakan untuk merumuskan strategi pengembangan UKM sektor unggulan.
Dengan adanya strategi pengembangan yang terintegrasi diharapkan UKM menjadi kegiatan ekonomi yang memiliki nilai tambah dan berdaya saing tinggi, tidak hanya memiliki keunggulan komparatif melainkan keunggulan kompetitif. Menurut Tambunan (2002) karakteristik UKM yang memiliki keunggulan kompetitif adalah sebagai berikut: (a) memiliki kualitas SDM yang baik, (b) pemanfaatan teknologi yang optimal, (c) mampu melakukan efisiensi dan meningkatkan produktivitas, (d) mampu meningkatkan kualitas produk, (e) memiliki akses promosi yang luas, (f) memiliki sistem manajemen kualitas yang terstruktur, (g) sumber daya modal yang memadai, (h) memiliki jaringan bisnis yang luas, dan (i) memiliki jiwa kewirausahaan.

\section{METODE}

Penelitian ini menggunakan strategi penelitian studi kasus (case study). Studi kasus ini dilaksanakan di beberapa UKM yang secara spasial berada di Kotamadya Bandung, Propinsi Jawa Barat. UKM yang dipilih menjadi sampel adalah UKM yang sudah mampu ekspor, subkontraktor Usaha Besar, dan memiliki nilai penjualan yang cenderung meningkat. Pengumpulan data dilakukan dari bulan Agustus 2010 sampai dengan bulan Desember 2010, dengan menggunakan multiple source of evidence, yaitu wawancara, studi arsip dan observasi langsung. Wawancara digunakan sebagai sumber data utama. Para stakeholders yang menjadi responden untuk pemerolehan data penelitian adalah perwakilan dari Dinas Koperasi dan UMKM Propinsi Jawa Barat, pemilik, manajer, dan para karyawan UKM. Pendekatan yang digunakan untuk merumuskan strategi pengembangan UKM adalah (1) location quotient, (2) diamond cluster model, dan (3) Analisis SWOT. Ketiga pendekatan tersebut adalah sebagai berikut:

\section{Location Quotient}

Miller dan Wright (1991), Isserman (1997), dan Hood (1998) mengemukakan bahwa metode Location Quotient (LQ) digunakan untuk mengidentifikasi komoditas unggulan di suatu wilayah. Teknik LQ merupakan salah satu pendekatan yang umum digunakan dalam model ekonomi basis sebagai langkah awal untuk memahami sektor kegiatan yang menjadi pemacu pertumbuhan. Teknik ini menyajikan perbandingan relatif antara kemampuan suatu sektor di daerah yang diselidiki dengan kemampuan yang sama pada daerah yang lebih luas. Satuan yang digunakan sebagai ukuran untuk menghasilkan koefisien LQ adalah jumlah tenaga 
kerja, hasil produksi, atau satuan lain yang bisa digunakan sebagai kriteria.

Jika memakai nilai produksi sebagai bahan pertimbangan dalam perhitungan $\mathrm{LQ}, \mathrm{LQ}$ lebih besar daripada 1 (LQ > 1), mempunyai arti komoditas tersebut merupakan sektor basis. LQ lebih kecil daripada 1 ( $\mathrm{LQ}<1$ ), mempunyai arti produksi komoditas tersebut belum mencukupi kebutuhan konsumsi di daerah yang bersangkutan dan pemenuhannya didatangkan dari daerah lain. LQ sama dengan $1(\mathrm{LQ}=1)$, mempunyai arti produksi komoditas yang bersangkutan hanya cukup untuk kebutuhan daerah setempat.

Rumus LQ dengan dasar pertimbangan nilai PDRB adalah sebagai berikut:

$$
\mathrm{LQ}=\frac{\mathrm{V}_{\mathrm{x}}^{\mathrm{R}} / \mathrm{V}^{\mathrm{R}}}{\mathrm{V}_{\mathrm{x}}^{\mathrm{N}} / \mathrm{V}^{\mathrm{N}}}
$$

Di mana:

$V_{x}^{R}=$ umlah PDRB pada suatu sektor $\mathrm{x}$ di daerah $\mathrm{R}$

$V^{R}=$ jumlah PDRB seluruh sektor di daerah $\mathrm{R}$

$V_{x}^{N}=$ jumlah PDRB pada suatu sektor $\mathrm{x}$ di daerah referensi $\mathrm{N}$

$V^{N}=$ jumlah PDRB seluruh sektor di daerah referensi $\mathrm{N}$

\section{Diamond Cluster Model}

Porter (1990) mengemukakan bahwa cluster diartikan sebagai "geographic concentrations of firms, suppliers, related industries, and specialized institutions that occure in a particular field in a nation, state or city." Definisi yang lain mengenai clusters adalah "geographical concentration of industries that gain performance advantages through co-location". Clusters menunjukkan hubungan antara perusahaan yang juga menyediakan complementary service, termasuk jasa konsultan, penyedia jasa pendidikan dan training, lembaga-lembaga keuangan, professional associations dan institusi-institusi pemerintah.

Dari Diamond Cluster Model seperti yang tersaji pada Gambar 1, dapat diidentifikasi terdapat 4 (empat) komponen, yaitu: pertama, faktor input (input factor) yang merupakan variabel-variabel yang sudah ada dalam cluster industri seperti sumber daya manusia (human resource), sumber daya modal (capital resource), infrastruktur fisik (physical infrastructure), infrastruktur informasi (information infrastructure), infrastruktur ilmu pengetahuan dan

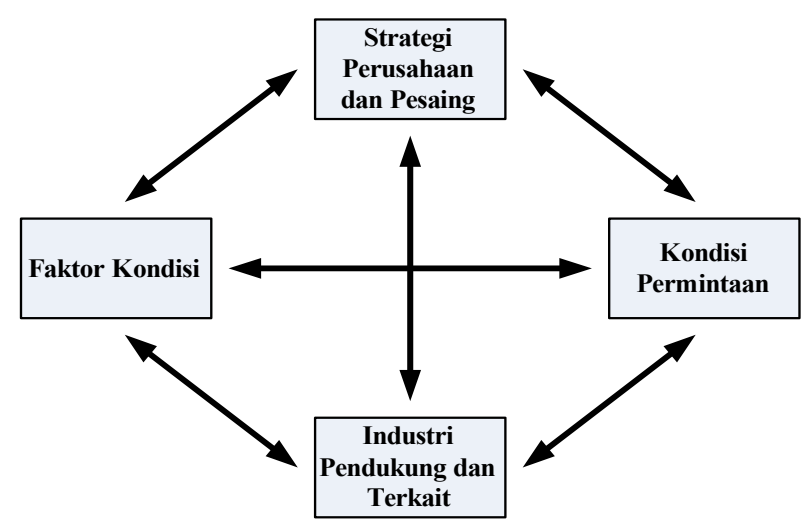

Gambar 1. Diamond Cluster Model

Sumber: Porter, (1990)

teknologi (scientific and technology infrastructure), infrastruktur administrasi (administrative infrastructure), dan sumber daya alam (natural resource). Kedua, kondisi permintaan (demand condition) yang berkaitan dengan sophisticated and demanding local customer. Semakin maju suatu masyarakat dan semakin demanding pelanggan dalam negeri, maka industri akan selalu berupaya untuk meningkatkan kualitas produk atau melakukan inovasi guna memenuhi keinginan pelanggan lokal yang tinggi.

Ketiga, industri pendukung dan terkait (related and supporting industries) untuk efisiensi dan sinergitas dalam clusters, terutama dalam hal transaction cost, sharing teknologi, informasi, dan keahlian tertentu yang dapat dimanfaatkan oleh industri atau perusahaan lainnnya, yaitu untuk meningkatkan daya saing dan produktivitas. Keempat, strategi perusahaan dan pesaing (context for firm, strategy, and rivalry) yang dapat mendorong perusahaan untuk melakukan peningkatan kualitas produk dan inovasi. Dengan adanya persaingan yang sehat dan ketat, perusahaan akan mencari strategi yang cocok dan berupaya untuk meningkatkan efisiensi.

\section{Analisis SWOT}

Analisis SWOT (Strength, Weakness, Opportunities, Threats) biasa digunakan untuk mengevaluasi kesempatan dan tantangan di lingkungan bisnis maupun pada lingkungan internal perusahaan (Kuncoro, 2005). Untuk memudahkan dalam implementasi analisis SWOT diperlukan konstruksi matriks SWOT, dengan mengkombinasikan faktor kekuatan, kelemahan, peluang, dan ancaman. Matriks SWOT disajikan pada Tabel 1. 
Tabel 1. Matriks Analisis SWOT

\begin{tabular}{|c|c|c|}
\hline Faktor Eksternal $\quad$ Faktor Internal & $\begin{array}{c}\text { STRENGTHS (S) } \\
\text { (Daftar semua kekuatan } \\
\text { yang dimiliki) }\end{array}$ & $\begin{array}{c}\text { WEAKNESSES(W) } \\
\text { (Daftar semua kelemahan } \\
\text { yang dimiliki) }\end{array}$ \\
\hline $\begin{array}{l}\text { OPPORTUNITIES (S) } \\
\text { (Daftar semua peluang yang dapat } \\
\text { diidentifikasi) }\end{array}$ & $\begin{array}{c}\text { Strategi SO } \\
(\text { Growth })\end{array}$ & $\begin{array}{c}\text { Strategi WO } \\
\text { (Stability) }\end{array}$ \\
\hline $\begin{array}{l}\text { THREATS (T) } \\
\text { (Daftar semua ancaman yang dapat } \\
\text { diidentifikasi) }\end{array}$ & $\begin{array}{c}\text { Strategi ST } \\
\text { (Diversification) }\end{array}$ & $\begin{array}{l}\text { Strategi WT } \\
(\text { Defend })\end{array}$ \\
\hline
\end{tabular}

Sumber: Kuncoro, (2005)

Dari matriks analisis SWOT seperti yang tersaji pada Tabel 1, dapat diidentifikasi terdapat 4 (empat) strategi, yaitu: Pertama, strategi SO yang merupakan strategi untuk menggunakan semua kekuatan yang dimiliki untuk memanfaatkan peluang yang ada. Kedua, strategi WO yang merupakan strategi mengatasi semua kelemahan dengan memanfaatkan peluang yang ada. Ketiga, strategi ST yang merupakan strategi menggunakan semua kekuatan untuk menghindari dari semua ancaman. Keempat, strategi WT yang merupakan strategi menekan semua kelemahan dan mencegah semua ancaman.

Dengan menggunakan tiga pendekatan tersebut, maka tahapan penelitian yang dikembangkan adalah sebagai berikut: (a) menginisiasi sektor UKM unggulan yang paling berpotensi untuk dikembangkan. Indeks LQ akan dijadikan pedoman untuk menginisasi sektor unggulan UKM tersebut, (b) mengidentifikasi keunggulan bersaing UKM berdasarkan pendekatan diamond cluster model. Keunggulan bersaing ini akan mencakup faktor input, kondisi permintaan, industri pendukung dan terkait, dan strategi perusahaan dan pesaing, (c) mengklasifikasikan keunggulan bersaing UKM menjadi faktor internal dan eksternal, (d) menentukan faktor-faktor yang menjadi kekuatan (strength), kelemahan (weakness), peluang (opportunity), dan ancaman (threats), yang selanjutnya disajikan dalam matrik SWOT, (e) merumuskan strategi berdasarkan kombinasi dari kekuatan (strength), kelemahan (weakness), peluang (opportunity), dan ancaman (threats), dan (f) penetapan prioritas strategi pengembangan UKM, dan (g) implementasi strategi terpilih.

\section{HASIL DAN PEMBAHASAN}

\section{Identifikasi Sektor Unggulan UKM}

Ada 9 (sembilan) sektor ekonomi UKM yang akan dikembangkan, yaitu: (a) pertanian, peternakan, kehutanan dan perikanan, (b) pertambangan dan penggalian, (c) industri pengolahan, (d) listrik, gas dan air bersih, (e) bangunan, (f) perdagangan, hotel dan restoran, (g) pengangkutan dan komunikasi, (h) keuangan, persewaan dan jasa perusahaan, dan (i) jasa lainnya. Untuk menentukan sektor UKM unggulan dari 9 sektor tersebut digunakan indeks LQ. Perhitungan dan analisis LQ didasarkan dengan membandingkan data PDRB setiap sektor UKM dengan akumulasi data PDRB untuk semua sektor di Kotamadya Bandung. Nilai PDRB yang menjadi dasar perhitungan digunakan nilai PDRB atas dasar harga konstan. Hasil hitungan nilai LQ yang berupa nilai indeks tersaji pada Tabel 2. Berdasarkan hasil hitungan yang tersaji pada Tabel 2, sektor UKM yang menjadi unggulan untuk dikembangkan adalah sektor industri pengolahan (sebut IKM) dengan besarnya nilai indeks LQ adalah 4,277. Nilai indeks LQ UKM sektor industri pengolahan merupakan nilai terbesar di antara indeks sektor-sektor lainnya. Dengan demikian, berdasarkan nilai indeks LQ ini dapat ditarik sebuah kesimpulan bahwa UKM sektor Industri Pengolahan yang paling memiliki potensi untuk terus dikembangkan.

Tabel 2. Indek LQ Sektor UKM

\begin{tabular}{lc}
\hline \multicolumn{1}{c}{ Sektor } & Indek LQ \\
\hline Pertanian, Peternakan, Kehutanan dan & 1,083 \\
Perikanan & \\
Pertambangan dan Penggalian & 0,000 \\
Industri Pengolahan & 4,277 \\
Listrik, Gas dan Air Bersih & 0,829 \\
Bangunan & 0,617 \\
Perdagangan, Hotel dan Restoran & 0,527 \\
Pengangkutan dan Komunikasi & 0,235 \\
Keuangan, Persewaan dan Jasa Perusahaan & 0,801 \\
Jasa Lainnya & 0,616 \\
\hline
\end{tabular}

Sumber: Rahmana dkk. (2010)

\section{Identifikasi Keunggulan Bersaing UKM}

Berdasarkan hasil penelitian yang dilakukan Rahmana dkk. (2010), keunggulan bersaing UKM sektor industri pengolahan berdasarkan Diamond Cluster Model yang meliputi faktor input, kondisi permintaan, industri pendukung dan terkait, dan strategi perusahaan dan pesaing. Faktor input atau kondisi terdiri atas teknologi proses produksi 
yang relatif modern, tingkat penjualan yang terus meningkat, mengandalkan modal sendiri, dan adanya gap kemampuan antara pimpinan dan karyawan. Faktor kondisi permintaan terdiri atas industri-industri besar sebagai konsumen utama dan permintaan produk presisi, sparepart mesin industri, semakin meningkat. Faktor strategi perusahaan dan pesaing terdiri atas pengembangan sistem penjaminan kualitas (ISO), pembuatan produk presisi berbasis CNC-CAD-CAM, kerja sama dengan lembaga pendidikan terkemuka (ITB dan Polman), dan pelayanan konsumen 24 jam. Sementara itu, faktor industri pendukung dan terkait terdiri atas subkontraktor industri-industri besar, ketersediaan bahan baku, dan outsourching pekerjaan. Keempat faktor keunggulan bersaing beserta komponenkomponennya divisualisasikan pada Gambar 2.

Keunggulan bersaing UKM diklasifikasikan menjadi faktor internal yang meliputi faktor kekuatan dan kelemahan, serta faktor eksternal yang meliputi faktor peluang, dan ancaman. Pertama, faktor kekuatan UKM sektor industri pengolahan adalah: UKM mampu membuat produk yang presisi, UKM telah menjadi subkontraktor industri-industri besar, UKM memiliki alat produksi yang modern, seperti mesin CNC, Omzet UKM dari tahun ke tahun mengalami peningkatan yang signifikan, UKM mengandalkan kekuatan modal sendiri, dan UKM memiliki orientasi dan motivasi untuk sertifikasi sistem manajemen kualitas ISO. Kedua, faktor-faktor kelemahan UKM sektor industri pengolahan adalah: UKM belum belum tersertifikasi ISO, terdapat kesenjangan kemampuan antara pimpinan dan karyawan UKM dalam hal teknis operasional dan manajerial, setiap keputusan yang harus diambil masih bertumpu pada direktur, dan Awareness terhadap kualitas produk dan proses belum sepenuhnya dipahami oleh anggota organisasi UKM. Ketiga, faktor-faktor peluang bagi UKM sektor industri pengolahan adalah: beberapa industri besar telah menjadi konsumen utama UKM, adanya pengakuan yang positif dari industri besar terhadap kualitas produk yang dibuat UKM, bekerja sama dengan lembaga pendidikan terkemuka, seperti ITB dan Politeknik Manufaktur Bandung, dan permintaan produk presisi, sebagai sparepart mesin industri semakin meningkat. Keempat, faktor-faktor yang menjadi ancaman bagi UKM sektor industri pengolahan adalah: produk impor lebih berkualitas, ketersediaan baku menurun, konsumen utama akan beralih ke industri lain jika UKM belum tersertifikasi ISO, dan diberlakukannya pasar bebas.

\section{Strategi Pengembangan UKM}

Hasil identifikasi terhadap kekuatan, kelemahan, peluang, dan ancaman di UKM sektor industri pengolahan, kemudian dilanjutkan dengan pembuatan matrik SWOT untuk menentukan alternatif strategi. Matrik ini menggambarkan bagaimana peluang dan ancaman eksternal yang dihadapi oleh UKM sektor industri pengolahan disesuaikan dengan kekuatan dan kelemahan yang dimiliki oleh UKM sektor industri pengolahan. Strategi pengembangan UKM yang didasarkan pada kombinasi antara strength, weakness, opportunity, dan threats.

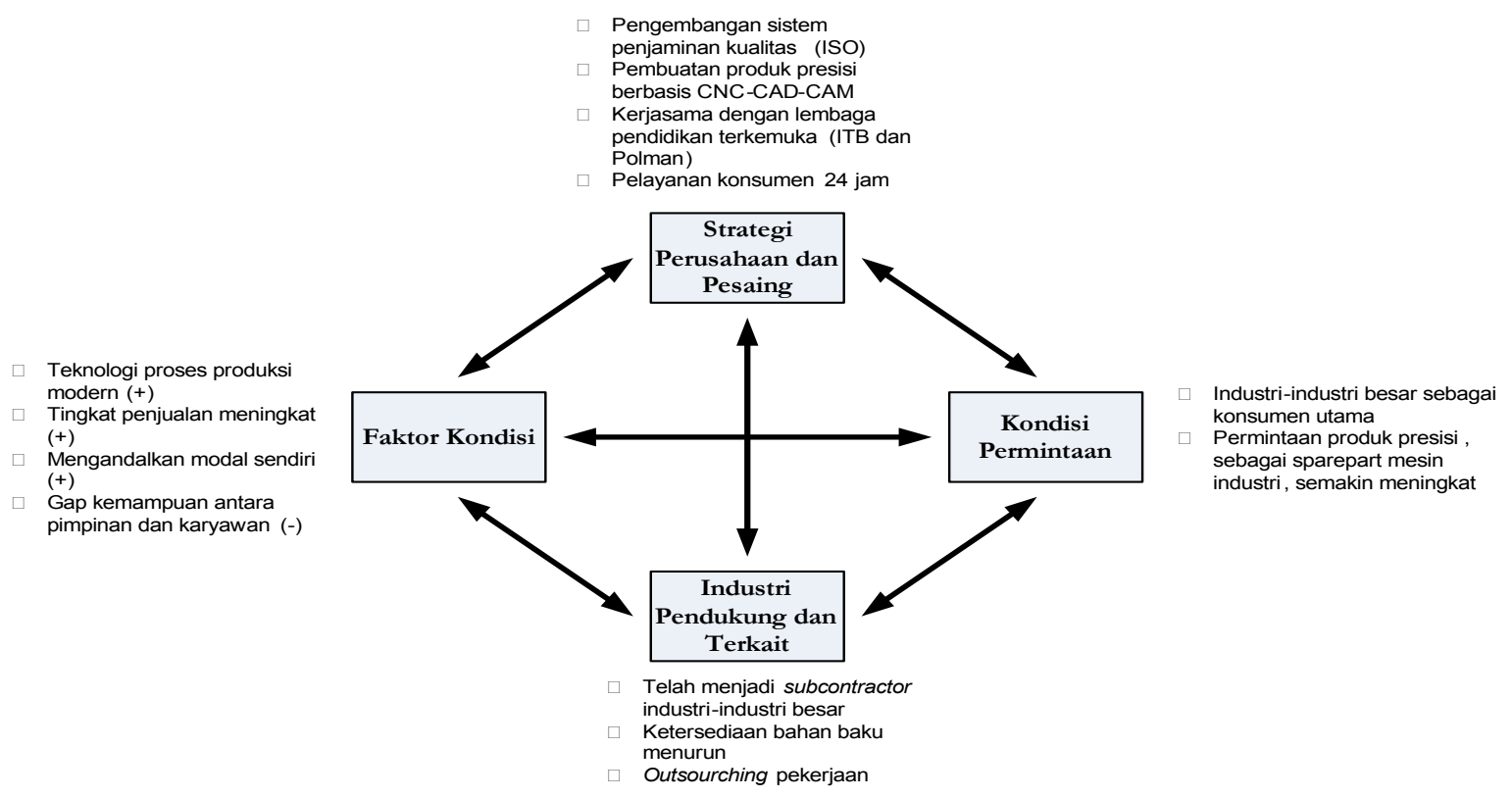

Gambar 2. Keunggulan Bersaing UKM Berdasarkan Diamond Cluster Model Sumber: Rahmana dkk. (2010) 
Strategi SO adalah strategi untuk menggunakan semua kekuatan yang dimiliki untuk memanfaatkan peluang yang ada. Berdasarkan hasil kajian, strategi SO yang dirumuskan adalah sebagai berikut: menjaga dan meningkatkan kualitas produk, peningkatan sistem manajemen kualitas ke arah sertifikasi penjaminan kualitas (ISO), peningkatan kemitraan dengan industri-industri besar, melakukan Research dan Development dalam rangka pengembangan produk. Strategi WO adalah strategi untuk mengatasi semua kelemahan dengan memanfaatkan peluang yang ada. Berdasarkan hasil kajian, strategi WO yang dirumuskan adalah sebagai berikut: peningkatan sistem manajemen kualitas ke arah sertifikasi penjaminan kualitas (ISO), peningkatan kompetensi karyawan, peningkatan tingkat pendidikan karyawan, peningkatan kesadaran terhadap pentingnya kualitas produk dan proses.

Strategi ST adalah strategi yang menggunakan semua kekuatan untuk menghindari dari semua ancaman. Berdasarkan hasil kajian, strategi ST yang dirumuskan adalah sebagai berikut: meningkatkan kualitas produk, peningkatan sistem manajemen kualitas ke arah sertifikasi penjaminan kualitas (ISO), optimalisasi penggunaan teknologi produksi $\mathrm{CAD}$, CAM, dan CNC, peningkataan kerja sama dengan supplier bahan baku, dan diversifikasi produk. Strategi WT adalah strategi yang menekan semua kelemahan dan mencegah semua ancaman Berdasarkan hasil kajian, strategi WT yang dirumuskan adalah sebagai berikut: peningkatan sistem manajemen kualitas ke arah sertifikasi penjaminan kualitas (ISO), peningkatan kesadaran terhadap pentingnya kualitas produk dan proses, dan Peningkataan kerja sama dengan supplier bahan baku.

\section{Penetapan Prioritas Strategi Pengembangan UKM}

Pemetakan prioritas strategi pengembangn UKM Sektor Pengolahan di Propinsi Jawa Barat dilakukan menggunakan analisis terhadap Faktor Internal dan Eksternal, yaitu Internal Factor Analysis Summary (IFAS) dan Eksternal Factor Analysis Summary (EFAS). Tahapan dalam menyusun tabel Internal Factor Analysis Summary (IFAS) dan Eksternal Factor Analysis Summary (EFAS) adalah (a) menentukan faktor-faktor yang menjadi kekuatan dan kelemahan serta peluang dan ancaman UKM, (b) memberikan bobot masing-masing faktor dari skala 0,0 (tidak penting) sampai dengan 1,0 (sangat penting), di mana semua bobot tersebut jumlahnya tidak melebih skor total 1,00, (c) menghitung rating untuk masing-masing faktor dengan memberikan skala mulai dari 1 (di bawah rata-rata) sampai dengan 4 (sangat baik), dan (d) menghitung nilai skor yang merupakan perkalian antara bobot dan rating. Nilai rating kekuatan dan kelemahan selalu bertolak belakang, begitu juga nilai rating peluang dan ancaman. Penentuan nilai bobot dan rating tersebut didasarkan pendapat pakar UKM dan para

Tabel 3. Matriks Internal Factor Analysis Summary

\begin{tabular}{|c|c|c|c|}
\hline Faktor-faktor Internal & Bobot & Rating & Nilai Skor \\
\hline \multicolumn{4}{|l|}{ Kekuatan } \\
\hline a. UKM telah menjadi subkontraktor industri-industri besar & 0,20 & 4 & 0,80 \\
\hline b. UKM mampu membuat produk yang presisi & 0,10 & 4 & 0,40 \\
\hline c. UKM sektor pengolahan memiliki alat produksi yang modern, seperti mesin CNC & 0,025 & 3 & 0,075 \\
\hline $\begin{array}{l}\text { d. Omzet UKM sektor pengolahan dari tahun ke tahun mengalami peningkatan yang } \\
\text { signifikan }\end{array}$ & 0,05 & 3 & 0,15 \\
\hline $\begin{array}{l}\text { e. UKM sektor pengolahan mengandalkan kekuatan modal sendiri (tidak memiliki } \\
\text { pinjaman ke bank) }\end{array}$ & 0,05 & 3 & 0,15 \\
\hline $\begin{array}{l}\text { f. UKM sektor pengolahan memiliki orientasi dan motivasi untuk sertifikasi sistem } \\
\text { manajemen kualitas ISO }\end{array}$ & 0,20 & 4 & 0,80 \\
\hline Sub Total & $\mathbf{0 , 6 2 5}$ & & 2,375 \\
\hline \multicolumn{4}{|l|}{ Kelemahan } \\
\hline a. UKM sektor pengolahan belum belum tersertifikasi ISO & 0,15 & 2 & 0,30 \\
\hline $\begin{array}{l}\text { b. Terdapat kesenjangan kemampuan antara pimpinan dan karyawan UKM sektor } \\
\text { pengolahan dalam hal teknis operasional dan manajerial }\end{array}$ & 0,075 & 1 & 0,075 \\
\hline c. Setiap keputusan yang harus diambil masih bertumpu pada direktur & 0,05 & 1 & 0,05 \\
\hline $\begin{array}{l}\text { d. Awareness terhadap kualitas produk dan proses belum sepenuhnya dipahami oleh } \\
\text { anggota organisasi UKM sektor pengolahan }\end{array}$ & 0,10 & 1 & 0,10 \\
\hline Sub Total & $\mathbf{0 , 3 7 5}$ & & $\mathbf{0 , 5 2 5}$ \\
\hline Total & $\mathbf{1 , 0 0}$ & & 2,90 \\
\hline
\end{tabular}


Tabel 4. Matriks Eksternal Factor Analysis Summary

\begin{tabular}{|c|c|c|c|}
\hline Faktor-faktor Eksternal & Bobot & Rating & Nilai Skor \\
\hline \multicolumn{4}{|l|}{ Peluang } \\
\hline a. Beberapa industri besar telah menjadi konsumen utama UKM sektor pengolahan & 0,15 & 3 & 0,45 \\
\hline $\begin{array}{l}\text { b. Adanya pengakuan yang positif dari industri besar terhadap kualitas produk yang } \\
\text { dibuat UKM sektor pengolahan }\end{array}$ & 0,015 & 4 & 0,06 \\
\hline $\begin{array}{l}\text { c. Bekerja sama dengan lembaga pendidikan terkemuka, seperti ITB dan Politeknik } \\
\text { Manufaktur Bandung }\end{array}$ & 0,025 & 3 & 0,075 \\
\hline d. Permintaan produk presisi, sebagai sparepart mesin industri semakin meningkat & 0,075 & 3 & 0,225 \\
\hline Sub Total & $\mathbf{0 , 2 6 5}$ & & $\mathbf{0 , 8 1 0}$ \\
\hline \multicolumn{4}{|l|}{ Ancaman } \\
\hline a. Produk impor lebih berkualitas & 0,25 & 1 & 0,25 \\
\hline b. Ketersediaan bahan baku menurun & 0,15 & 1 & 0,15 \\
\hline $\begin{array}{l}\text { c. Konsumen utama akan beralih ke industri lain jika UKM sektor pengolahan belum } \\
\text { tersertifikasi ISO }\end{array}$ & 0,25 & 2 & 0,50 \\
\hline d. Diberlakukannya pasar bebas & 0,085 & 2 & 0,17 \\
\hline Sub Total & $\mathbf{0 , 7 3 5}$ & & $\mathbf{1 , 0 7 0}$ \\
\hline Total & 1,00 & & 1,880 \\
\hline
\end{tabular}

pimpinan UKM. Hasil pembobotan, rating, dan nilai skor untuk masing-masing faktor internal dan eksternal disajikan pada Tabel 3 dan Tabel 4.

Dari tabel 3 diperoleh hasil bahwa nilai skor untuk faktor kekuatan adalah 2,375 dan nilai skor untuk faktor kelemahan adalah 0,525. Sementara itu, dari Tabel 4 diperoleh hasil bahwa nilai skor untuk faktor peluang adalah 0,810 dan nilai skor untuk faktor ancaman adalah 1,070. Nilai skor kekuatan ternyata di atas nilai skor kelemahan dengan selisih nilai (+) 1,850, sedangkan nilai skor peluang ternyata di bawah nilai skor ancaman dengan selisih nilai (-) 0,260 .

Dari hasil identifikasi faktor-faktor tersebut dan penentuan selisih skor, kemudian digambarkan dalam diagram SWOT, di mana faktor kekuatan dan peluang diberi nilai positif (+), sedangkan faktor kelemahan dan ancaman diberi nilai (-). Diagram SWOT tersebut disajikan pada Gambar 3. Dari nilai total masing-masing faktor, selain dapat digambarkan dalam diagram SWOT juga disajikan dalam rumusan matrik SWOT, yang akan menggambarkan nilai skor dari masing-masing kombinasi strategi seperti yang disajikan pada Tabel 5.

Berdasarkan diagram kartesius SWOT yang disajikan pada Gambar 3 dihasilkan bahwa UKM berada pada kuadran IV artinya bahwa strategi pengembangan UKM adalah strategi ST, yaitu strategi menggunakan kekuatan (strength) untuk mengatasi ancaman (threat). Strategi ini dikenal pula dengan istilah strategi diversifikasi (diversification). Jika mengacu pada strategi ini, maka sebaiknya UKM melakukan diversifikasi produk presisi

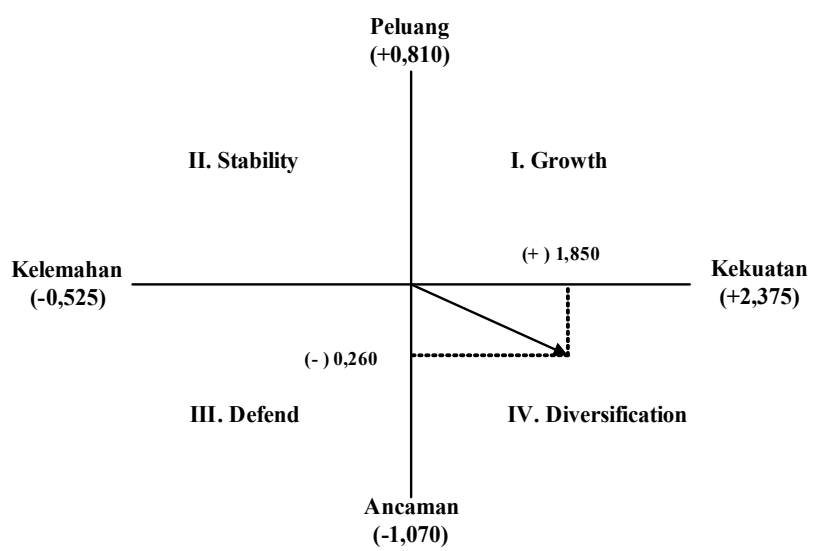

Gambar 3. Diagram Kartesius SWOT

Tabel 5. Kombinasi Strategi Kuantitatif

\begin{tabular}{|c|c|c|}
\hline EFAS IFAS & $\begin{array}{c}\text { Kekuatan } \\
\text { (Strength) - S }\end{array}$ & $\begin{array}{c}\text { Kelemahan } \\
\text { (Weakness) - W }\end{array}$ \\
\hline $\begin{array}{l}\text { Peluang } \\
\text { (Opportunity) - O }\end{array}$ & $\begin{array}{l}\text { Strategi SO: } \\
=2,375+0,810 \\
=3,185\end{array}$ & $\begin{array}{l}\text { Strategi WO: } \\
=0,525+0,810 \\
=1,335\end{array}$ \\
\hline $\begin{array}{l}\text { Ancaman } \\
(\text { Threat })-\mathrm{T}\end{array}$ & $\begin{array}{l}\text { Strategi ST: } \\
=2,375+1,070 \\
=3,445\end{array}$ & $\begin{array}{l}\text { Strategi WT: } \\
=0,525+1,070 \\
=1,595\end{array}$ \\
\hline
\end{tabular}

dengan menggunakan teknologi CNC, CAD, dan CAM. Dengan dipercayanya sebagai subkontraktor industri-industri besar, membuka kesempatan yang sangat luas untuk mengembangkan dan memberikan penawaran kepada industri besar untuk mengerjakan spare part mesin-mesin industri, dengan kualitas yang tidak kalah bersaing dengan produk impor karena pada dasarnya UKM tersebut mempunyai 
teknologi yang canggih dalam proses produksinya, didukung pula oleh kemampuan UKM itu sendiri membuat produk-produk yang presisi.

Kombinasi strategi, yang disajikan pada Tabel 5, merupakan analisis model kuantitatif perumusan strategi, yang didasarkan pada jumlah nilai skor pada masing-masing faktor yang ada pada masing-masing strategi baik itu untuk strategi SO, WO, ST, dan WT. Berdasarkan Tabel 5 tersebut, maka UKM sebaiknya memanfaatkan strategi ST karena mempunyai nilai skor tertinggi jika dibandingkan dengan yang lain yaitu sebesar 3,445. Selanjutnya diikuti dengan strategi ST dengan nilai 3,185, WT dengan nilai 1,595, dan WO dengan nilai 1,335. Mendasari pada hasil analisis matrik SWOT dengan analisis model kuantitatif untuk mendapatkan perumusan yang efektif, yaitu strategi ST yaitu strategi strategi menggunakan kekuatan (strength) untuk mengatasi ancaman (threat), maka implementasi strategi ST adalah (1) meningkatkan kualitas produk melalui peningkatan kualitas proses dengan memanfaatkan (a) penggunaan teknologi canggih, (b) kemampuan karyawan UKM dalam membuat produk presisi, (c) pengembangan program-program quality improvement, seperti program Gugus Kendali Mutu, dan (d) pengembangan Sistem Manajemen Mutu berbasis ISO, dan (2) membina kerja sama yang intensif dengan para supplier untuk memperoleh pasokan bahan baku yang secara kuantitas dan kualitas sangat memadai.

\section{SIMPULAN}

Strategi pengembangan UKM sektor Industri Pengolahan dapat digunakan sebagai upaya untuk mewujudkan agar UKM menjadi kegiatan ekonomi yang memiliki nilai tambah dan berdaya saing tinggi, tidak hanya memiliki keunggulan komparatif melainkan keunggulan kompetitif,sehingga UKM dapat berkiprah di pasar domestik dan pasar internasional. Rumusan strategi pengembangan UKM didasarkan pada 2 (dua) pendekatan, yaitu strategi berdasarkan analisis diagram kartesius SWOT dan kombinasi strategi matrik SWOT. Pertama, berdasarkan diagram kartesius SWOT diperoleh hasil bahwa UKM berada pada kuadran IV dengan strategi diversifikasi. Implementasi strategi diversifikasi ini caranya adalah UKM melakukan diversifikasi produk-produk presisi dengan menggunakan teknologi CNC, CAD, dan CAM untuk spare part mesin-mesin industri besar dengan kualitas yang tidak kalah bersaing dengan produk-produk impor. Kedua, berdasarkan analisis kombinasi strategi kuantitatif diperoleh hasil bahwa prioritas strategi yang sebaiknya diterapkan oleh UKM adalah strategi ST, yaitu strategi strategi menggunakan kekuatan (strength) untuk mengatasi ancaman (threat). Implementasi strategi ini adalah dengan meningkatkan kualitas produk melalui peningkatan kualitas proses dan membina kerja sama yang intensif dengan para supplier untuk memperoleh pasokan bahan baku yang secara kuantitas dan kualitas sangat memadai bagi UKM.

\section{DAFTAR PUSTAKA}

Anon, 2005. Promoting Small and Medium Enterprises with a Clustering Approach: A Policy Experience from Indonesia, Journal of Small Business Management, Vol 43 No. 2, pp. 138-154.

Hafsah, M.J., 2004. Upaya Pengembangan Usaha Kecil dan Menengah (UKM), Infokop, Nomor 25 Tahun $\mathrm{XX}$, hal 40-44.

Hood, 1998. Economic Analysis: A Location Quotient, Primer, Principal Sun Region Associates, Inc.

Husband, S. and Purnendu, M., 1999. A Conceptual Model for Quality Inetgrated Management in Small and Medium Size Enterprise, International Journal of Quality \& Reliability Management, Vol. 16 No. 7, pp. 699-713.

Isserman, Andrew, M., 1997. The Location Quotient Approach for Estimating Regional Economic Impacts, AIP Journal.

Kuncoro, M., 2005. Strategi: Bagaimana Meraih Keunggulan Kompetitif?, Erlangga, Jakarta.

Miller, M.M, and Wright, G.N., 1991. Location Quotient Basic Tool for Economic Development Analysis, Economic Development Riview, 9(2), 65.

Porter, 1990. Keunggulan Bersaing: Menciptakan dan Mempertahankan Kinerja Unggul, Binarupa Aksara, Jakarta.

Prawirokusumo, S., 2001. Ekonomi Rakyat: Konsep, Kebijakan, dan Strategi, BPPE, Yogyakarta.

Rahmana, A., dkk. 2010. Strategi UKM Sektor Manufaktur Propinsi Jawa Barat dalam Meningkatkan Daya Saing Berdasarkan Diamond Cluster Model, Penelitian yang tidak Dipublikasikan, BPPM, Universitas Widyatama, Bandung.

Situmorang, J., 2008. Strategi UMKM dalam Menghadapi Iklim Usaha yang Tidak Kondusif, Infokop, Volume 16, Hal 88-101.

Tambunan, T., 2002. Usaha Kecil dan Menengah di Indonesia: Beberapa Isu Penting, Salemba, Jakarta.

Tambunan, T., 2005. Promoting Small and Medium Enterprises with a Clustering Approach: A Policy Experience from Indonesia, Journal of Small Business Management, Vol 43 No. 2, pp. 138-154.

Winarni, E.S., 2006. Strategi Pengembangan Usaha Kecil melalui Peningkatan Aksesibilitas Kredit Perbankan, Infokop Nomor 29, Tahun XXII. 